\title{
O GARANTISMO JURÍDICO NO DIREITO SINDICAL
}

\section{Francisco José Gomes da Silva}

Pós-Doutorando em Direitos Humanos pela Universidade de Salamanca, Espanha. Doutorando e Mestrando em Ciências Jurídicas pela Universidade Autónoma de Lisboa. Doutor em Direito Constitucional pela Universidade de Fortaleza. Desembargador do Tribunal Regional do Trabalho da Sétima Região. Professor Adjunto da Universidade de Fortaleza (UNIFOR). E-mail: <franze@secrel.com.br>.

\section{Rosendo Freitas de Amorim}

Professor Titular do Programa de Pós-Graduação em Direito Constitucional da Universidade de Fortaleza (UNIFOR). E-mail: <rosendo@unifor.br>.

\begin{abstract}
Resumo: Ao longo dos anos, o garantismo jurídico se afirmou como uma forma de impelir as autoridades a exercerem o poder de forma humanizada. Dessa maneira, no Brasil, estabeleceu-se a democracia, ao tempo em que foram introduzidos direitos e garantias fundamentais na vida de todos os cidadãos por meio da Constituição Federal de 1988. o texto magno consagrou a máxima de que todo o poder emana do povo; assim, não possível a aceitação da negligência em relação à afirmação dos direitos e deveres codificados. 0 garantismo aliado ao constitucionalismo gera efeitos positivos na vida dos cidadãos, pois ambos detêm objetivos similares, ou seja, almejam a eficácia plena dos direitos e garantias fundamentais na vida de todos, mormente em relação aos trabalhadores. Não se pode olvidar que a origem do garantismo se encontra na seara penal; entretanto, seus reflexos podem ser vistos por todos os ramos jurídicos. 0 dinamismo teórico das normas jurídicas serve para adequar as regras aos fenômenos sociais que emergem no seio social. A interpretação da norma deve ser permeada pela incidência dos reflexos do princípio da dignidade da pessoa humana e da solidariedade, uma vez que tais cátedras se encontram no texto de abertura constitucional (preâmbulo), que, embora não tenha forma normativa, serve de inspiração para o trato das relações sociais. A identificação valorativa dos princípios estabelece um processo eficaz de comunicação entre a sociedade e o direito, tornando essa relação cada vez mais democratizada. A solidariedade e a dignidade são fontes primárias da democracia, da fraternidade e do garantismo. No que pertine à matéria laboral, a incidência do garantismo é bem aceita, uma vez que o direito do trabalho resulta de uma história de lutas e conquistas, os trabalhadores são a força motriz da economia nacional, e a mão de obra humana é indispensável para o desenvolvimento da nação.
\end{abstract}

Palavras-chave: Garantismo. Direitos fundamentais. Constitucionalismo. Trabalhadores.

Sumário: 1 Introdução - 2 Garantismo jurídico - $\mathbf{3} 0$ garantismo e o direito do trabalho - análise do pensamento de Luigi Ferrajoli - 40 garantismo e o direito sindical - proteção do trabalhador 5 Conclusão - Referências 


\section{Introdução}

0 presente artigo aborda uma temática pertinente para a compreensão da legislação laboral moderna, a saber, o garantismo jurídico no direito sindical. Primeiramente, faz-se imperioso esclarecer que o jusfilósofo Luigi Ferrajoli foi o responsável pela disseminação da ideia do "garantismo" em ambiência internacional.

Como a própria nomenclatura assevera, o garantismo se propõe a efetivar as garantias legais, impondo a melhor interpretação das normas em benefício do cidadão, além de limitar o poder do ente ficto estatal.

Analisando o arcabouço normativo do ordenamento brasileiro, pode ser asseverado que, ao longo das décadas, as Constituições angariaram direitos aos trabalhadores. Dessa forma, as inovações legislativas e as construções jurisprudenciais devem atender aos preceitos constitucionais, cuidando para não violar nenhuma das garantias positivadas.

A problemática advinda da inovação da interpretação legislativa não pode ser exercida com a atividade legislativa, mas deve ser vista como uma forma de efetivar os efeitos garantistas lecionados pelo filósofo Luigi Ferrajoli. Dessa maneira, cabe ao Poder Judiciário a tarefa de sumular matérias de modo a garantir a pacificação das decisões, a celeridade judicial e a segurança jurídica. Contudo, essa atividade não deve violar nenhuma cátedra constitucional.

O garantismo, surgido originariamente em matéria penal, tem o escopo de assegurar um processamento justo em momento anterior a uma eventual condenação. Em matéria laboral, o garantismo tem objetivo similar, pois busca entender as relações sociais estabelecidas para identificar de forma justa os direitos e deveres inerentes a cada parte.

A evolução jurídica ressignificou o papel das partes que compõem uma relação de trabalho com o propósito de destinar ao Estado Democrático de Direito o protagonismo na imposição de soluções justas e pacíficas para os conflitos. Desde então, restaram superadas as questões relacionadas à vingança, e a perseguição da virtuosa justiça foi confiada à autoridade estatal.

Nesse passo, os objetivos deste trabalho são: esclarecer como o garantismo, em que pese ter sido originado no direito penal, pode gerar reflexos positivos em todas as searas jurídicas; e demonstrar os efeitos garantistas na justiça do trabalho. A metodologia utilizada para o desenvolvimento deste estudo é bibliográfica e investigativa, com a utilização de livros, jurisprudência e publicações científicas sobre a matéria.

De modo a prover melhor respaldo teórico ao estudo, o presente trabalho conta com a fundamentação de autores reconhecidos na área do direito constitucional, como Manoel Gonçalves Ferreira Filho, Luigi Ferrajoli, André Ramos Tavares e Rui 
Stoco. Vale ressaltar que as argumentações levantadas neste estudo são frutos da análise do pensamento externalizado pelo próprio Luigi Ferrajoli, que concedeu inúmeras entrevistas e palestras disponíveis ao público interessado em ambiência virtual.

Com o fito de demonstrar a imperatividade das normas constitucionais avalizadas pelo garantismo, o estudo em tela se propõe a: explicitar o conceito do garantismo jurídico e sua natureza jurídica; demonstrar como o garantismo interage com os demais ramos do direito, influencia na postura dos magistrados e promove a tutela dos trabalhadores. Para tanto, também será alvo de estudo o garantismo em relação às searas trabalhistas e sindicais.

O estudo em questão buscou esclarecer os reflexos progressistas do garantismo na seara trabalhista, justificando os motivos que legitimam a validade desse modelo teórico na efetivação dos direitos emergidos a partir das lutas das classes que almejam condições de trabalho dignas e justas.

\section{Garantismo jurídico}

A organização social humana foi iniciada após a demonstração dos primeiros lapsos da razão humana de forma objetiva. Nesse momento, o homem passou a viver em bando para garantir a própria proteção. Esses grupamentos antecederam a forma moderna de Estado e sua regulamentação política, legislativa e econômica.

Outro avanço perceptível foi a escrita nas paredes das cavernas, que retrata a história e demonstra o momento em que foi iniciada a divisão do trabalho. A convivência humana provocou a criação de um senso comum pautado pela razão, como a imposição de regras de convivência e solução de problemas. A racionalização de ideias das pessoas que formavam o grupo incentivou a inteligência humana em diversos campos de conhecimento (CELLARIUS, 1774).

Os primeiros grupamentos de trocas de objetos e mercadorias incentivaram o mocambo e, posteriormente, a criação da moeda e das práticas comerciais organizadas. A convivência tranquila entre os povos proporcionou a circulação de riquezas e aprimorou as relações comerciais. A agricultura e a pecuária estabilizaram a convivência humana, possibilitando a formação das antigas civilizações com a fundação das primeiras cidades.

A formação dos clãs foi possível a partir da identificação de traços culturais, de escrita e linguísticos. Nesse tempo, houve a necessidade da gestão da vida coletiva com o surgimento do Estado. 0 ente estatal emerge da forma retratada nas obras filosóficas de autoria de pensadores como Thomas Hobbes, John Locke 
e Jean Jacques Rousseau. O surgimento do Estado como forma de organizar a sociedade, após a Revolução de 1789, culminou com a codificação das leis.

À luz da doutrina contemporânea, pode-se asseverar que o garantismo não é uma temática estreante no mundo jurídico; na realidade, desde os primórdios do positivismo se faz presente nas legislações. No século XVII, o garantismo se afirmou como uma doutrina invocada para cobrar do Estado um olhar humanizado sobre as demandas populares levadas à apreciação do monarca.

Nesse passo, vale rememorar a marcante obra Dos delitos e das penas, escrita por Cesare Beccaria, no século XVIII, no contexto iluminista. Tal escrito denunciou os abusos decorrentes das punições estatais. 0 iluminismo cravou sua importância na história como um dos movimentos mais belos e significativos na conquista dos direitos humanos. Em referência ao que foi dito, Vicentino (2000, p. 235) assevera que:

Nos séculos XVII e XVIII, período áureo do Estado absolutista, o desenvolvimento e o crescimento da sociedade burguesa esbarraram nos entraves remanescentes do mundo feudal. As teorias políticas de Maquiavel e Bossuet justificavam um estado que se mostrava cada vez mais avesso ao dinamismo capitalista - era o Antigo Regime. Vários intelectuais passaram a criticá-lo, anunciando um mundo contemporâneo, um novo Estado, novas instituições, novos valores, condizentes com o progresso econômico, científico e cultural em andamento. Na segunda metade do século XVIII, esses valores estruturariam os fundamentos teóricos que levariam à eclosão da Revolução Industrial, da independência dos Estados Unidos e, posteriormente da Revolução Francesa, acontecimentos que marcaram o início do mundo contemporâneo.

Não custa rememorar que, naquela época, Beccaria advogou a tese de que a aplicação do jus puniendi deveria ser imposta em conformidade com o grau de lesão ocasionado a um bem juridicamente tutelado, insurgindo-se contra a imposição de "penas cruéis e infamantes", expressão posteriormente incorporada à Constituição da América do Norte, promulgada em 1787.

$\mathrm{Na}$ verdade, o garantismo é um modelo normativo de direito que nasceu na seara penal e se impôs como um limite às punições estatais, bem como garantia de direitos e de liberdade ao indivíduo. Segundo Sayonara Grillo C. L. da Silva (2011, p. 276), o garantismo pode ser compreendido como:

[...] proposta teórica de um garantismo - que expande seus domínios para além do direito penal e acena com uma revalorização dos 
aspectos publicistas dos direitos do trabalho - pretendemos refletir sobre uma concepção de direitos fundamentais, com incidência direta sobre os locais de trabalho. Busca-se estabelecer pressupostos para a eficácia horizontal dos direitos civis, políticos e de participação dos trabalhadores nas empresas, compreendidos como verdadeiros direitos fundamentais dos mais débeis.

Nesse contexto, o garantismo pode ser estendido a todos os direitos fundamentais, pois, além da liberdade, abrange os direitos sociais e políticos que representam a face do constitucionalismo moderno que fundamenta a democracia considerada como elemento indispensável ao progresso do Estado Liberal de Direito. O garantismo emerge para refutar tratamentos degradantes destinados aos trabalhadores como os adotados em outrora na forma narrada por Nascimento (2001, p. 38-39):

A imposição de condições de trabalho pelo empregador, a exigência de excessivas jornadas de trabalho, a exploração das mulheres e menores, que eram a mão de obra mais barata, os acidentes com os trabalhadores no desempenho das suas atividades e a insegurança quanto ao futuro e aos momentos nos quais fisicamente não tivessem condições de trabalhar foram as constantes da nova era no meio proletário, às quais podem-se acrescentar também os baixos salários.

A constitucionalização de um Estado deve enfrentar etapas, como a identificação do estágio de desenvolvimento social, para que sejam inseridos no seio coletivo novos valores, como se perfaz a fraternidade processual que desconstrói as relações maléficas estabelecidas entre as partes, cedendo lugar à garantia da solidariedade.

\subsection{Conceito}

O convívio social passou a ser possível a partir do estabelecimento de uma relação social de caráter organizacional político. Desse modo, os primeiros grupamentos humanos se uniram e se fortaleceram até a união das vozes de um povo reunido em determinado território resultar na criação de sua Constituição ou ordem normativa superior. O desenvolvimento da lógica e da razão apoiou a estruturação civilizatória de modo a favorecer o bem comum. 
O modelo normativo garantista foi consagrado na obra Direito e razão, escrito publicado há mais de duas décadas. No estudo apontado, o jusfilósofo Luigi Ferrajoli apresenta a magnitude do garantismo e a importância de seus reflexos nos mais diversos os ramos jurídicos. 0 garantismo centra sua lógica argumentativa no indivíduo e em sua liberdade ante o arbítrio do Estado. Por essa razão, a codificação é importante para estabelecer limites, direitos e deveres para determinada nação.

Notadamente, o garantismo tem aplicação privilegiada na seara criminal, pois, desde o século XVII, esse modo de interpretar o direito exigiu das autoridades um olhar mais humanizado no que concerne à figura do réu. Assim, o direito penal se impõe como o exemplo principal do garantismo, que aborda, ainda, o estudo de duas grandes rupturas provocadas na base jurídica estatal.

A primeira grande ruptura faz referência à transição do Estado pré-moderno jusnaturalista para o Estado moderno legislativo de direito fundado no princípio da legalidade. Entretanto, a positivação das leis não acarretou a persecução da justiça esperada pelo povo, e a frustração dessa expectativa conduziu à ocorrência de uma segunda ruptura.

Destarte, a segunda ruptura explicada por Ferrajoli trata da evolução do princípio da legalidade estrita para o Estado constitucional baseado em constituições rígidas. Nesse passo, a validade de uma norma passa a ser condicionada a uma prévia análise de conformidade formal e substancial.

A segunda ruptura torna inapropriado o antigo brocado jurídico auctoritas non veritas face legem, ou seja, para ser válida basta que a lei emane de autoridade competente. Dessa maneira, Ferrajoli explica que a validação de uma lei é condicionada à sua adequação formal e substancial, isto é, mais que emanar de uma autoridade competente, é preciso que se atenda aos preceitos, conteúdos e significados constitucionais.

O Estado Constitucional de Direito deve funcionar em complemento ao Estado Legislativo de Direito. Essa medida é uma das formas de atingir a justiça e a harmonia social, finalidades maiores do Estado Democrático de Direito.

Assim sendo, o garantismo não se perfaz como uma doutrina e nem se apresenta como uma teoria; trata-se, na verdade, de um modo de ver o direito, visualizando a persecução penal do Estado ao longo dos séculos. 0 garantismo é uma teoria crítica e uma filosofia política do direito; portanto, aplicar o direito literal foge aos cânones ou à ideia da concepção garantista. Nas lições de Rosa (2003, p. 19-20), tem-se que:

O garantismo jurídico apesar de ter sua origem vinculada ao Direito Penal, evoluiu para alcançar foros de Teoria do Direito. Luigi Ferrajoli 
indica quatro frentes garantistas. A primeira está vinculada à revisão da teoria da validade, que preconiza uma diferenciação entre validade/material e vigência/formal das normas jurídicas. A segunda frente pretende o reconhecimento de uma dimensão substancial da democracia, suplantando o caráter meramente procedimental desta. Já na terceira, do ponto de vista do Juiz, se propõe uma nova maneira de ver a sujeição à lei somente por ser lei - aspecto formal - pretendendo que a sujeição se dê somente quando conjugadas a forma e conteúdo das normas. Por fim, observa a relevância da ciência jurídica, cujo papel deixa de ser meramente descritivo, mas ganha contornos críticos e de projeção do futuro. Com efeito, a Teoria Geral do Garantismo, entendida como modelo de Direito, está baseada no respeito à dignidade da pessoa humana e seus Direitos Fundamentais, com sujeição formal e material das praticas jurídicas aos conteúdos constitucionais. Isso porque, diante da complexidade contemporânea, a legitimação do Estado Democrático de Direito deve suplantar a mera democracia formal, para alcançar a democracia material, na qual os Direitos Fundamentais devem ser respeitados, efetivados e garantidos, sob pena da de legitimação paulatina das instituições estatais. Dito de outra forma, tendo-se em vista a supremacia Constitucional dos direitos positivados no corpo de Constituições rígidas ou nela referidos (CF, art. 5ำ $\S 2^{\circ}$ ), como a brasileira de 1988 , e do principio da legalidade, a que todos os poderes estão submetidos, surge à necessidade de garantir esses direitos a todos os indivíduos.

Nesses termos, faz-se imperioso o reconhecimento de que o garantismo se impõe como um sistema de limites a todos os poderes estatais na esfera pública e privada, em âmbito nacional e internacional. 0 modelo interpretativo do garantismo é fruto de uma reformulação idealizada pelo eminente jurista retroapontado, que inovou a doutrina com aportes progressistas no que tange à defesa dos direitos fundamentais.

Dissipadas as incertezas em relação à insurgência do garantismo sobre todos os ramos jurídicos, incluindo a seara trabalhista, é possível afiançar que sua aplicabilidade representa a adoção de uma conduta austera e incisiva de respeito às garantias fundamentais por parte dos operadores do direito.

\subsection{Natureza jurídica}

As normas jurídicas se originam da necessidade da organização da vida humana, e tais regramentos são doados da função de regência dos relacionamentos 
sociais; portanto, nesse rol se inclui o direito do trabalho. A influência legislativa nas atividades laborais é motivada por se tratar de relacionamentos humanos, notadamente da exploração do homem pelo próprio homem.

Assim sendo, a evolução das normas tem o condão de conquistar condições de trabalho ideais para garantir dignidade aos trabalhadores. Bom é que se diga que o princípio da dignidade da pessoa humana deve imperar nas relações de trabalho, pois essa tendência é fruto da constitucionalização do direito laboral.

Nesse passo, o garantismo deve ser compreendido como um sistema de normas que privilegia a tutela de direitos destinados aos homens. 0 Estado é um ente ficto de poder organizado pelo homem; portanto, precisa ser pautado na potencialização dos melhores interesses sociais. Não é razoável a aceitação da opressão e do tolhimento das garantias conquistadas pelos trabalhadores.

A consciência humana é a grande precursora das inovações legislativas. Desse modo, o direito emerge do âmago do próprio homem. A intervenção pública se faz necessária, mas deve ser limitada para não haver o abuso de direito por parte do ente estatal. Destarte, o garantismo se afirma como uma doutrina de natureza jurídica legalista e protecionista que impõe o homem como ator principal e finalidade maior da regulamentação normativa.

As normas trabalhistas detêm notória força protetiva; por isso, nessa área jurídica, o garantismo age de forma a promover a dignidade laboral humana, afiançando direitos como: jornada de trabalho justa, proteção ao trabalho da mulher e do menor, direitos previdenciários, vedação de renúncia a direitos, entre outros.

A elaboração das normas jurídicas laborais emana de três fontes, a saber: estatal, classista e regulamentar. O monopólio estatal regulamenta a vida em sociedade; as classes trabalhadoras propõem regras relacionadas às relações laborais; e o caráter regulamentar emerge do poder diretivo do empregador.

\subsection{0 garantismo e os demais ramos do direito, a postura dos magistrados e a tutela constitucional dos trabalhadores}

Os maiores reflexos da Revolução Francesa foram seus ideais de liberdade, de igualdade e de fraternidade, que passaram a influenciar a interpretação das normas, impondo-se como um novo paradigma para as noções de direitos humanos. O garantismo impõe seu modelo interpretativo como uma forma de concretizar as aspirações do contrato social de modo a realizar os objetivos da ordem pública e social (STRECK, 2009). 0 garantismo tem por objetivo materializar 
a tutela constitucional do trabalhador, afastando a ideia de que se trata somente de uma norma de boa intenção.

O garantismo busca efetivar as liberdades individuais pretendidas desde a disseminação do pensamento iluminista que inspiraram a criação dos direitos e garantias fundamentais (CADEMATORI, 1999). Assim, as normas laborais foram compiladas de forma a tutelar os interesses da parte mais fragilizada da relação: os trabalhadores. Esse modelo de interpretação e aplicabilidade normativa zela pela dignidade humana e legitima a atuação estatal em prol do homem na forma pretendida desde o final da Segunda Guerra Mundial, momento em que o indivíduo foi inserido no centro da tutela do ordenamento jurídico.

No que pertine à realização da justiça, cumpre aos magistrados a adoção de uma postura altiva e independente, guardando respeito intangivel ao conteúdo magno, sem prescindir da coragem necessária para a evolução de suas convicções na busca pelos ideais de aperfeiçoamento da justiça em conformidade com a realidade de seu tempo.

Aos magistrados cabe o papel de interpretar e aplicar as normas, que são âncoras cognitivas formadoras de conteúdo jurisprudencial. Decisões coerentes preservam a confiança da coletividade e a coesão das respostas judiciais aos litígios.

A jurisprudência tradicionalista denota considerável influência sobre a maioria das decisões trabalhistas; entretanto, a reconstrução de pensamentos se impõe em razão da necessária concatenação da justiça com a realidade de seu tempo. A todo o momento, surgem novas relações sociais, emergindo conflitos que, por vezes, carecem da destinação de um olhar mais humanizado à parte hipossuficiente, ou seja, ao empregado.

É inegável o esforço extraordinário de muitos juízes que se rebelam diante de entendimentos jurisprudenciais predominantes e tradicionalistas, muitas vezes incompatíveis com os princípios que regem o direito laboral, notadamente o reequilíbrio da disparidade de forças entre empregador e empregado.

Decisões que desprezam a incidência da garantia da aplicação dos direitos humanos desconstroem uma história de lutas que sacrificaram milhares de vidas de trabalhadores. Estes lutaram por todas as conquistas prelecionadas, hoje, no texto constitucional e na compilação da legislação trabalhista.

A Consolidação das Leis do Trabalho (CLT), efetiva carta de cidadania dos trabalhadores brasileiros, constitui-se em elemento fundamental para civilização das relações e redução da desigualdade existente nas relações de trabalho. Todavia, a CLT não foi o primeiro instrumento de tutela das relações laborais. A luta pelos direitos dos trabalhadores foi estreada, em meados do século XX, pelos congressos sindicais, que iniciaram a construção de direitos como: limitação de 
jornada de trabalho; vedação do trabalho infantil; idade mínima para o início de trabalho; isonomia laboral entre homens e mulheres, entre outros.

Em 1934, a Constituição vigente à época abrigou em seu bojo a criação da justiça do trabalho, a instituição do salário mínimo e o tempo determinado para a jornada de trabalho. Contudo, para efetivar tais disposições constitucionais, foram necessárias muitas lutas entre patrões e empregados. Os trabalhadores adquiriram maturidade e consciência para entender que conquistar direitos é tão importante quanto efetivá-los.

Destarte, a CLT é exatamente a reunião dos direitos paulatinamente conquistados pelos trabalhadores. Ao longo dos anos, essas legislações sofreram reformas em benefício e em prejuízos dos trabalhadores; portanto, o cenário laboral, no Brasil, passou por muitas alterações. A CLT determinou o direito ao descanso semanal, mas a remuneração desse descanso somente foi reconhecida na década de 50 (cinquenta).

A Constituição de 1946 estabeleceu o direito de greve, garantia violada durante o período ditatorial. Dessa maneira, no ano de 1988 , esse direito foi reafirmado para os trabalhadores. Retomando a década de 60 (sessenta), pode ser dito que a CLT passou a abranger a tutela de direitos dos trabalhadores rurais e domésticos negligenciados outrora; ademais, garantiu o 13ํㅗa sário a todos os trabalhadores.

O contexto histórico do reconhecimento de direitos laborais é muito controverso. Apesar da obtenção de conquistas, houve perdas significativas, como a permutação da estabilidade decenal pela instituição do Fundo de Garantia por Tempo de Serviço (FGTS). Como pode ser entendido, o FGTS não é uma conquista, pois não guarda origem protetiva e retirou o direito de permanência do trabalhador no emprego.

É bem verdade que a inovação jurisprudencial, na esfera superior, vem proferindo decisões arbitrárias em face dos trabalhadores. Nesse contexto, é possivel mencionar o caso de trabalhadores que são dispensados em razão de portarem doenças que não geram estabilidade, demonstrando a ausência de limite ao poder de dispensa do empregador.

Vale ainda reconhecer que os acidentes de trabalho não são previstos em legislações laborais, mas em regramentos previdenciários datados do ano de 1991, precisamente na Lei o 8.213 , em seu art. 118, o qual dispõe:

O segurado que sofreu acidente do trabalho tem garantida, pelo prazo mínimo de doze meses, a manutenção do seu contrato de trabalho na empresa, após a cessação do auxílio-doença acidentário, independentemente de percepção de auxílio-acidente. 
Não obstante, podem ser destacadas garantias constitucionais, como: salário mínimo nacionalmente unificado, piso salarial, décimo terceiro salário, jornada de trabalho diária de 8 (oito) horas, licenças paternidade e maternidade, férias, vedação da automação etc.

Antes de promover o vilipêndio aos regramentos tutelares laborais, faz-se imperioso o respeito à história das lutas de classes, bem como a observância ao garantismo que impõe o atendimento aos direitos humanos em contexto internacional e aos direitos fundamentais em ambiência nacional. Lecionando sobre a concretização do garantismo na seara trabalhista, a Desembargadora Sayonara Grillo C. L. da Silva (2011, p. 11, online) ensina que:

Um primeiro campo para a concretização do garantismo está no estabelecimento de limites ao exercício do poder diretivo e disciplinar dos empregadores. No limite, trata-se de indagar sobre as possibilidades de controle (pela jurisprudência) do poder de comando (do empregador) nos marcos de uma sociedade de controle (e não apenas de vigilância). Conceitos jurídicos originários da dogmática civilista vêm sendo (bem) utilizados para conter e limitar o poder disciplinar e o poder de comando do empregador. Proibição de abuso de direito, responsabilidade por infligir dano moral, responsabilidade extrapatrimonial, boa-fé objetiva, são institutos que permitem ao direito dar conta de resolver progressivas demandas por dignidade pessoal nas relações laborais.

A autora retromencionada cita em seu texto a doutrina garantista capitaneada por Ferrajoli. Note-se:

El trabajo es una manifestación de la persona de la misma manera que lo son el pensamiento, palabra, la conciencia y otras similares. Como tal, no puede subordinarse a la lógica privada del mercado, sino que exige ser tutelado -como lo impone nuestra Constitución-contra las arbitrariedades de los poderes no solo públicos, sino también, y diría sobre todo, de los privados (FERRAJOLI, 2008, p. 291).

Observando o texto constitucional de 1988, percebe-se que o artigo 7 은 se revela como uma centelha protetiva, pois deflagra de forma ascendente um conteúdo afirmativo de direitos fundamentais inerentes aos trabalhadores. 0 objetivo maior é consagrar a tutela referenciada; nessa esteia, no caput do artigo anteriormente mencionado, pode ser lida a seguinte redação: "Outros direitos que 
visem à melhoria de sua condição social”. O desrespeito a tal regramento viola o princípio da vedação do retrocesso social. Leia-se:

Art. 7 ํ São direitos dos trabalhadores urbanos e rurais, além de outros que visem à melhoria de sua condição social:

I - relação de emprego protegida contra despedida arbitrária ou sem justa causa, nos termos de lei complementar, que preverá indenização compensatória, dentre outros direitos;

II - seguro-desemprego, em caso de desemprego involuntário;

III - fundo de garantia do tempo de serviço;

IV - salário mínimo, fixado em lei, nacionalmente unificado, capaz de atender a suas necessidades vitais básicas e às de sua família com moradia, alimentação, educação, saúde, lazer, vestuário, higiene, transporte e previdência social, com reajustes periódicos que Ihe preservem o poder aquisitivo, sendo vedada sua vinculação para qualquer fim;

V - piso salarial proporcional à extensão e à complexidade do trabaIho;

VI - irredutibilidade do salário, salvo o disposto em convenção ou acordo coletivo;

VII - garantia de salário, nunca inferior ao mínimo, para os que percebem remuneração variável;

VIII - décimo terceiro salário com base na remuneração integral ou no valor da aposentadoria;

IX - remuneração do trabalho noturno superior à do diurno;

$X$ - proteção do salário na forma da lei, constituindo crime sua retenção dolosa;

XI - participação nos lucros, ou resultados, desvinculada da remuneração, e, excepcionalmente, participação na gestão da empresa, conforme definido em lei;

XII - salário-família pago em razão do dependente do trabalhador de baixa renda nos termos da lei;

XIII - duração do trabalho normal não superior a oito horas diárias e quarenta e quatro semanais, facultada a compensação de horários e a redução da jornada, mediante acordo ou convenção coletiva de trabalho;

XIV - jornada de seis horas para o trabalho realizado em turnos ininterruptos de revezamento, salvo negociação coletiva; 
$X V$ - repouso semanal remunerado, preferencialmente aos domingos;

XVI - remuneração do serviço extraordinário superior, no mínimo, em cinqüenta por cento à do normal;

XVII - gozo de férias anuais remuneradas com, pelo menos, um terço a mais do que o salário normal;

$[\ldots]$

Em acréscimo ao sobredito, Mendes (2010, p. 145) ressalta que: "No tocante aos direitos e garantias individuais, mudanças que minimizem a sua proteção, ainda que topicamente, não são admissíveis". O legislador ordinário pode caminhar por um campo aberto de reconhecimento de direitos progressivos em benefício à preservação dos direitos fundamentais. Essa conduta é avalizada pela discricionariedade política e pelos reflexos garantista na seara legal trabalhista.

\section{0 garantismo e o direito do trabalho - análise do pensamento de Luigi Ferrajoli}

O garantismo pode ser entendido como uma teoria filosófica que remete aos fins do constitucionalismo em relação à atuação estatal. Desta feita, o Estado não pode adotar postura violadora dos direitos fundamentais traçados no bojo constitucional. O constitucionalismo se compromete com a defesa humana no sentido de frear condutas abusivas que se contraponham à democracia e à própria catalogação do direito positivado. No entendimento de Santiago da Silva (2017, p. 166):

O constitucionalismo pode ser analisado como sistema jurídico, como um conjunto de limites e de vínculos impostos a todos os poderes, ou como teoria do direito, em que a concepção de validade das leis não é aferida apenas sob critérios formais de produção legislativa, mas, também, sob o critério material, estando o conteúdo das normas sujeitos à necessária coerência com as normas constitucionais (FERRAJOLI, 2008). O seu teorizador foi o italiano Luigi Ferrajoli.

Considerando a afirmação apontada, pode ser dito que Ferrajoli iniciou o pensamento garantista de modo a valorar e proteger a figura humana do arbítrio estatal, ou seja, de garantir a eficácia dos direitos fundamentais.

Retomando a análise dos reflexos garantistas nas relações laborais, é preciso que seja reconhecida também a relevância do ativismo jurídico, tema estudado por 
inúmeros juristas, dentre os quais ganham destaque Mauro Cappelletti e Genaro Carrió. O segundo doutrinador referenciado é autor da célere frase "os juízes criam direito", pensamento que causou polêmica no mundo jurídico.

$\mathrm{Na}$ realidade, quando se fala em ativismo jurídico, não se pretende atribuir ao Poder Judiciário a competência para legislar. 0 entendimento que deve prevalecer é a possibilidade dos magistrados de adequarem a interpretação da norma da forma que melhor se amolde ao caso concreto. Para tanto, devem ser aplicados os direitos e garantias constitucionais, com privilégio aos direitos fundamentais.

Nesse passo, o garantismo serve como vetor para que seja realizada a interpretação normativa da forma mais vantajosa ao trabalhador hipossuficiente. Os princípios constitucionais, mormente a dignidade da pessoa humana, são cátedras de adequação da norma concretada à pacificação de conflitos sociais modernos. Por essa razão, os juízes que se dispõem a inovar a interpretação normativa são considerados proativos em sua atividade jurisdicional, ou seja, são os protagonistas da materialização da justiça. Considerando essa afirmação, pode ser mencionado o que ensina Ramos (2013, p. 386):

Si el activismo judicial fomenta y viabiliza el protagonismo del juez em el processo de creación del Derecho, es fácil constatar que por sobre la liberdad de los litigantes, y basta mismo por sobre el debido proceso legal (=Garantia), el leitmotiv donde se basará el discurso de motivación de la decisión judicial será el arbitro y el subjetivismo próprio de la autoridad estatal responsable pelo "acto de habla" representando em la sentencia. Y siempre que asi ocurre habrá la opresión del modelo semântico de processo jurisdiccional garantista, democrático y republicano que desde la Constitución se proyecta.

Os princípios são hábeis a essa finalidade por serem dotados de baixa densidade normativa e alta densidade valorativa. Essa ideia pertence ao doutrinador alemão Robert Alexy. A fluidez dos princípios proporciona a abertura do sistema normativo de forma a melhor adequar a norma ao caso concreto, desde que não haja violação aos preceitos maiores.

A ponderação de valores para a inovação da interpretação normativa não deve negligenciar os limites normativos da separação dos poderes, a segurança jurídica das decisões judiciais, e nem o tratamento isonômico devido a todos os cidadãos que integram o Estado Democrático de Direito pátrio.

Na perspectiva laboral, o garantismo enfrenta o desafio de manter as normas vigentes e conseguir novas conquistas a serem integradas no sistema que é tradicionalmente protecionista para o trabalhador. A modernização das normas 
é uma consequência da evolução das relações sociais; do contrário, haveria a atrofia das garantias normativas.

\section{0 garantismo e o direito sindical - proteção do trabalhador}

A partir da proteção ao trabalhador hipossuficiente é que se originam os demais princípios do direito laboral, tais como: a norma mais favorável, a condição mais benéfica, primazia da realidade (o fato em detrimento da forma), in dubio pro empregado, indisponibilidade dos direitos trabalhistas, intangibilidade salarial, inalterabilidade contratual lesiva (não prejuízo ao trabalhador), continuidade, entre outros. As normas trabalhistas são cogentes na defesa do empregado.

O tópico que ora se inicia tem o condão de criticar o sistema brasileiro de precedentes vinculantes. Como se sabe, não cabe ao Poder Judiciário o exercício da atividade legislativa; entretanto, a possibilidade da criação de súmula guarda previsão constitucional nos termos do artigo 103-A. Leia-se:

Art. 103-A. O Supremo Tribunal Federal poderá, de ofício ou por provocação, mediante decisão de dois terços dos seus membros, após reiteradas decisões sobre matéria constitucional, aprovar súmula que, a partir de sua publicação na imprensa oficial, terá efeito vinculante em relação aos demais órgãos do Poder Judiciário e à administração pública direta e indireta, nas esferas federal, estadual e municipal, bem como proceder à sua revisão ou cancelamento, na forma estabelecida em lei.

§1ํ A súmula terá por objetivo a validade, a interpretação e a eficácia de normas determinadas, acerca das quais haja controvérsia atual entre órgãos judiciários ou entre esses e a administração pública que acarrete grave insegurança jurídica e relevante multiplicação de processos sobre questão idêntica.

§2ํㅗ Sem prejuízo do que vier a ser estabelecido em lei, a aprovação, revisão ou cancelamento de súmula poderá ser provocada por aqueles que podem propor a ação direta de inconstitucionalidade.

§3ำ Do ato administrativo ou decisão judicial que contrariar a súmula aplicável ou que indevidamente a aplicar, caberá reclamação ao Supremo Tribunal Federal que, julgando-a procedente, anulará o ato administrativo ou cassará a decisão judicial reclamada, e determinará que outra seja proferida com ou sem a aplicação da súmula, conforme o caso. 
O ordenamento jurídico pátrio abriga um conjunto sumular destinado, em tese, a promover a pacificação das decisões, a celeridade judicial e a segurança jurídica. A súmula é o resultado da criação de pequenos verbetes extraídos de julgamentos de casos similares. No Brasil, as primeiras súmulas remontam do ano de 1963, fato que, pelo tempo de permanência desses precedentes, permite afirmar que já constituem uma tradição no ordenamento pátrio.

Entretanto, não se pode olvidar que as súmulas emitidas por tribunais superiores podem ocasionar a fragilização dos interesses sociais, incluindo nesse rol a classe dos trabalhadores representados pelos seus respectivos sindicatos.

A aplicabilidade da lei tem por escopo a realização da justiça baseada no princípio fonte do sistema jurídico moderno, a saber, a dignidade da pessoa humana. Destarte, na oportunidade da interpretação normativa, o operador do direito deve destinar retilínea observância ao cumprimento dos preceitos constitucionais, sob pena de causar prejuízos à ordem pública e à paz social, finalidades maiores do Estado Democrático de Direito.

Nessa perspectiva, pode ser colacionado o equivocado entendimento externado pelo Tribunal Superior do Trabalho no bojo da Súmula no 369, uma vez que seu conteúdo normativo se contrapõe ao que dita o inciso VIIII do artigo 8o do texto constitucional. Observe-se:

\section{CLT}

Art. 8ํㅡ livre a associação profissional ou sindical, observado o seguinte:

[...]

VIII - é vedada a dispensa do empregado sindicalizado a partir do registro da candidatura a cargo de direção ou representação sindical e, se eleito, ainda que suplente, até um ano após o final do mandato, salvo se cometer falta grave nos termos da lei.

Súmula no 369 do TST

DIRIGENTE SINDICAL. ESTABILIDADE PROVISÓRIA (redação do item I alterada na sessão do Tribunal Pleno realizada em 14.09.2012) Res. 185/2012, DEJT divulgado em 25, 26 e 27.09.2012.

I - É assegurada a estabilidade provisória ao empregado dirigente sindical, ainda que a comunicação do registro da candidatura ou da eleição e da posse seja realizada fora do prazo previsto no art. 543, §5, da CLT, desde que a ciência ao empregador, por qualquer meio, ocorra na vigência do contrato de trabalho. 
II - 0 art. 522 da CLT foi recepcionado pela Constituição Federal de 1988. Fica limitada, assim, a estabilidade a que alude o art. 543, §3.ำ da CLT a sete dirigentes sindicais e igual número de suplentes. III - O empregado de categoria diferenciada eleito dirigente sindical só goza de estabilidade se exercer na empresa atividade pertinente à categoria profissional do sindicato para o qual foi eleito dirigente.

IV - Havendo extinção da atividade empresarial no âmbito da base territorial do sindicato, não há razão para subsistir a estabilidade.

$\mathrm{V}$ - O registro da candidatura do empregado a cargo de dirigente sindical durante o período de aviso prévio, ainda que indenizado, não lhe assegura a estabilidade, visto que inaplicável a regra do §3ํ do art. 543 da Consolidação das Leis do Trabalho.

A norma constitucional não delimita o número de dirigentes sindicais agraciados pela estabilidade provisória; porém, a súmula retrocolacionada restringe a essa garantia somente a 7 (sete) dirigentes. Não parece razoável a limitação sumular, pois esse regramento viola o que determina a norma magna.

No caso em tela, verifica-se afronta ao texto constitucional, bem como ao princípio da razoabilidade. Ante o sobredito, pode ser asseverado que o magistrado pode invocar os princípios como fundamentação de decisões judiciais. Robert Alexy, em suas lições, apregoa que os princípios são mandamentos de otimização que devem ser cumpridos na medida do possível, em conformidade com reais possibilidades jurídicas existentes.

Assim, o magistrado poderá invocar a constitucionalização do direito para refutar a delimitação do número de dirigentes com direito à estabilidade, em virtude de a súmula apontada desrespeitar uma norma constitucional. O posicionamento que opta pela aplicabilidade da norma constitucional expressa a não aceitação tácita do caráter invasor de matérias sumuladas em todos os ramos do direito.

As súmulas são resultados de matérias jurídicas postas de forma isonômica em decisões judiciais reiteradas. Esse conteúdo jurisprudencial é compactado em verbetes que passam a ditar regras, mandamentos e formas de cumprimento no plano fático sobre o que já foi previamente decidido no plano jurídico.

Destaque-se o papel do Poder Judiciário na concretização dos direitos, principalmente em relação às garantias fundamentais. O Poder Judiciário é conclamado pela sociedade para exercer uma postura dinâmica na tutela desses direitos, e essa postura identifica o que se entende por ativismo judicial.

0 ativismo referenciado não se comunica com a questão de políticas públicas ou qualquer resquício de interferência entre os poderes da União. Nesse caso, o ativismo se restringe ao processo na aplicação dos ditames constitucionais em 
busca da persecução da justiça, mas não deve violar preceitos constitucionais prevalentes.

Os magistrados funcionam como exegetas da lei; portanto, devem interpretar e seguir os preceitos normativos, sem violar suas lídimas finalidades. 0 lado desfavorável da liberdade da interpretação normativa é a disseminação evidente da insegurança jurídica.

Por essa razão, faz-se imperiosa a criação de normas para a emissão e aplicação de súmulas, de modo a vedar violações ao texto constitucional. Tal medida, certamente, atingiria as principais finalidades da matéria sumulada, quais sejam: a pacificação das decisões, celeridade processual e segurança jurídica.

0 efeito vinculante das súmulas, mormente as emitidas pelos tribunais superiores, deve-se impor como guias para as decisões dos demais órgãos ligados ao Judiciário por todo o país para construir um vínculo de uniformização do sistema, desde que seu conteúdo se harmonize com os ditames constitucionais.

Muitas críticas são lançadas à questão da prevalência do caráter vinculante das súmulas. Nesse passo, pode ser destacada a restrição da eficácia do princípio da persuasão do magistrado, pois seu trabalho se limitaria à mera aplicação de decisões. Não se pode aceitar que os julgadores retrocedam e desempenhem o mesmo papel de outrora destacado por Wambier (2009, p. 126): “Juízes eram vistos como seres inanimados, agindo como se fossem 'a boca da lei'. As teorias dedutivas eram capazes de explicar as decisões judiciais como se elas fossem o resultado de um raciocínio absolutamente lógico: Lei + fatos = decisão".

A obrigação de seguimento de precedentes normativos sumulares certamente impedirá o magistrado de repensar o direito e, por consequência imediata, cessará a marcha evolutiva das normas concretadas outrora. Tal ato é passível de ocasionar prejuízos à adaptação das leis e dos princípios, impedindo a solução eficaz e justa dos conflitos sociais modernos. Observando a problemática sob a ótica do garantismo, Rosa (2003, p. 19-20) destaca que:

[...] os Direitos Fundamentais desfilam com papel preponderante, ao propiciar a mensuração da concretização da Constituição. Estabelecem o que pode ser deliberado pelo Poder Legislativo e o que deve ser garantido pelo Poder Judiciário, mediante o controle da constitucionalidade material das normas, sujeitando os indivíduos, no Estado Democrático de Direito, somente às leis válidas, impedindo que eventuais maiorias violem direitos indissociáveis e construídos histórica e argumentativamente. A eficácia se constitui como parâmetro de aferição do grau de democracia material da sociedade (em graus). 0 garantismo jurídico, como visto, consiste na tutela de todos esses 
Direitos Fundamentais (liberdades e direitos sociais) assim estabelecidos pela ordem constitucional vigente, os quais representam os alicerces da existência do Estado Democrático de Direito, que o alimentam e são, assim, a base de democracia material.

Ao magistrado deve ser garantido o direito de realizar um juízo de subsunção, ou seja, deve ser garantido ao juiz o poder de decisão sobre a aplicabilidade da súmula ao caso concreto analisado. A opção voluntária do magistrado pela aplicação de regras fechadas (norma judicada ou decisões pacificadas pelos tribunais superiores) ao caso concreto não é considerada como uma violação ao princípio de persuasão racional do magistrado.

As súmulas se impõem como uma necessidade decorrente do exacerbado número de processos que justificam a lentidão do trabalho desenvolvido pelo Judiciário. Destarte, a criação de súmulas é benéfica, desde que não ultrapasse os limites do bom senso jurídico, observando-se os ditames constitucionais de forma retilínea.

É preciso garantir o exercício de um juízo de subsunção em relação à aplicação de um sistema aberto de regras, bem como a possibilidade do julgador se valer de um prévio juízo de ponderação anteriormente analisado pelos tribunais superiores, sem a obrigatoriedade de vincular sua decisão final. Dessa forma, súmulas vinculantes de caráter abusivo que ensejem prejuízos a regramentos constitucionais devem ter aplicabilidade refutada tanto em razão de sua ilegalidade quanto por figurarem como uma violação à materialização do garantismo na atividade sindical.

\section{Conclusão}

O estudo que ora se encerra pretendeu conceder uma visão constitucional sobre os reflexos do garantismo na seara trabalhista. Os direitos fundamentais, fundados na ideia de democracia, foram agrupados de modo a demonstrar a relevância da fraternidade e do garantismo na defesa do trabalhador hipossuficiente.

O garantismo veda o retrocesso normativo e a usurpação dos direitos trabalhistas; por isso, reafirma o caráter protecionista das normas laborais para tutelar a figura do hipossuficiente e explorado trabalhador brasileiro. Por essa razão, a obra de Luigi Ferrajoli encontra respaldo nas aspirações constitucionais brasileiras. 0 ordenamento normativo organiza a sociedade e limita os possíveis abusos que violam as perspectivas do Estado Democrático de Direito. 0 pensamento garantista é uma premissa do reconhecimento de que a tutela humana é o principal compromisso do ordenamento jurídico. 
Algumas construções jurisprudenciais modernas ainda tendem a desconsiderar a importância da tutela laboral em benefício dos empregadores. De forma a ilustrar essa afirmação, o estudo trouxe à baila a discussão sobre a incidência da Súmula no 369 emitida pelo Tribunal Superior do Trabalho e a violação à estabilidade reservada aos dirigentes sindicais abrigada pelo inciso VIII do artigo 8o da Consolidação das Leis Trabalhistas.

Entretanto, a maioria dos magistrados demonstra altivez e proatividade no momento em que julgam as demandas trabalhistas, tendo por escopo garantir a segurança jurídica e materializar a justiça. Essa postura afiança a importância da história do direito do trabalho no Brasil e impõe aos empregadores o dever de destinar aos empregados um tratamento mais humanizado.

0 garantismo chega à seara jurídica laboral com o encargo de impor respeito aos regramentos constitucionais, mormente no que tange aos princípios constitucionais da dignidade da pessoa humana e da vedação do retrocesso social. As inovações legislativas ou jurisprudenciais são legítimas, desde que potencializem o garantismo e não negligenciem os direitos e garantias fundamentais reservadas aos trabalhadores pátrios.

Por fim, bom é ressaltar que as lições progressistas de Ferrajoli contribuem para fortalecer a corrente jurisprudencial mais justa, a saber, a que privilegia a tutela aos direitos fundamentais laborais vigentes no Brasil.

\section{Legal guarantee in trade union law}

Abstract: Over the years, legal guaranty has been asserted as a way of pushing authorities to exercise power in a humane way. In this way, in Brazil, democracy was established, at a time when fundamental rights and guarantees were introduced in the lives of all citizens, through the Federal Constitution of 1988. The great text enshrined the maxim that all power emanates from the People, thus, it is not possible to accept negligence in relation to the affirmation of codified rights and duties. Garantism combined with constitutionalism generates positive effects on the lives of citizens, since both have similar objectives, that is, they aim at the full effectiveness of fundamental rights and guarantees in the lives of all, especially in relation to workers. One can not forget that the origin of the guaranty is in the criminal court, however, its reflexes can be seen by all legal branches. The theoretical dynamism of legal norms serves to adjust the rules to the social phenomena that emerge in the social sphere. The interpretation of the norm must be permeated by the impact of the reflexes of the principle of the dignity of the human person and of solidarity, since such chairs are found in the text of the constitutional opening (preamble) which, although not normative, serves as an inspiration for the Treatment of social relations. The value identification of the principles establishes an effective process of communication between society and law, making this relation more and more democratized. Solidarity and dignity are primary sources of democracy, fraternity and guaranty. Concerning labor matters, the incidence of garantism is well accepted, since labor law results from a history of struggle and conquest, workers are the driving force of the national economy and human labor is indispensable for the Development of the nation.

Keywords: Legal guarantee. Fundamental Rights. Constitutionalism. Workers. 
Summary: 1 Introduction - $\mathbf{2}$ Legal Garantism - $\mathbf{3}$ Garantism and labor law - analysis of the thinking of Luigi Ferrajoli - $\mathbf{4}$ The Garantism and the Right to union - protection of the worker - $\mathbf{5}$ Conclusion References

\section{Referências}

ALEXY, Robert. Teoria dos Direitos Fundamentais. São Paulo: Malheiros, 2008.

BRASIL. Constituição da República Federativa do Brasil (1988). Disponível em: <http://www. planalto.gov.br/constituicao/constitui\%C3\%A7ao.htm>. Acesso em: 02 abr. 2014.

BRASIL. Decreto-Lei n. 5.452, 01 de maio de 1943. Aprova a Consolidação das Leis do Trabalho. Disponível em: <http://www.planalto.gov.br/ccivil_03/decreto-lei/del5452.htm>. Acesso em: 12 abr. 2014.

BRASIL. Lei n. 8.213, 24 de julho de 1991. Dispõe sobre os Planos de Benefícios da Previdência Social e dá outras providências. Disponível em: <http://www.planalto.gov.br/ ccivil_03/leis//8213cons.htm/legislacao>. Acesso em: 03 abr. 2014.

CADEMARTORI, Daniela Mesquita Leutchuk; NEVES, Isadora Ferreira. Constitucionalismo garantista x Constitucionalismo Principialista: Aproximações entre Ferrajoli e Zagrebelsky. 1999.

CANOTILHO, J. J. Gomes. Direito Constitucional e Teoria da Constituição. Coimbra: Almedina, 1998.

CELLARIUS, Christopher. Compendium redacta. Roma: Published Geographica Antiqua, 1774.

BARROSO, Luis Roberto. Direito Constitucional Contemporâneo. São Paulo: Saraiva, 2013.

DORIA, Antonio de Sampaio. Direito Constitucional. 3. ed. São Paulo: Nacional, 1953.

FERRAJOLI, Luigi. Garantismo: uma discusión sobre derecho y democracia. Tradução para o espanhol de Andrea Greppi. Madrid: Trotta, 2006.

FERREIRA FILHO, Manoel Gonçalves. Curso de Direito Constitucional. 38. ed. São Paulo: Saraiva, 2012.

LEONARDO DA SILVA, Sayonara Grillo Coutinho. Direitos Fundamentais, Garantismo e Direito do Trabalho. Disponivel em: <http://www.tst.jus.br/documents/1295387/2684887/ Direitos+fundamentais,\%20garantismo+e+Direito+do+Trabalho>. Acesso em: 02 abr. 2017.

MENDES, Gilmar Ferreira. Curso de Direito Constitucional. 5. ed. São Paulo: Saraiva, 2010. MENDONÇA, José Vicente dos Santos. Vedação do retrocesso: o que é e como perder o medo. Rio de Janeiro: Lumen Juris, 2003.

MORAES, Guilherme Peña de. Curso de Direito Constitucional. 5. ed. São Paulo: Atlas, 2013. 
NASCIMENTO, Amauri Mascaro. Direito do Trabalho: história e teoria geral do direito do trabalho - relações individuais e coletivas. 26. ed. São Paulo: Saraiva, 2011.

NOVELINO, Marcelo. Constituição para concursos. Salvador: JusPodivm, 2010.

RAMOS, Glauco Gumerato. Actual debate em el procesalismo brasileño: garantismo ou activismo?. Universidad Nacional de Rosário. Disponível em: <file:///D:/Marina/ Desktop/2014/01_Monografias\%20e\%20Artigos\%202014.1/01_Trabalhos_Dr.\%20 Franz\%C3\%A9_UNIFOR/Ativismo_e_Garantismo_-_Glauco.pdf>. Acesso em: 02 maio 2017.

REALE, Miguel. Lições preliminares de Direito. 27. ed. São Paulo: Saraiva, 2012.

ROSA, Alexandre de Morais da. O que é o garantismo?. Florianópolis: Habitus, 2003.

ROUSSEAU, Jean Jaques. O Contrato Social. Porto Alegre: L\&PM, 2010.

SILVA, Alex Xavier Santiago da. Os Fundamentos do Processo Penal Solidário: Democracia, Fraternidade e Garantismo. 2017.

STOCO, Rui. Abuso de direito e má-fé processual. São Paulo: Revista dos Tribunais, 2002.

STRECK, Lênio Luiz. Hermenêutica jurídica em crise: uma exploração hermenêutica da construção do Direito. 8. ed. Porto Alegre: Livraria do Advogado, 2009.

TAVARES, André Ramos. Curso de Direito Constitucional. 10. ed. São Paulo: Saraiva, 2012.

WAMBIER, Tresa Arruda Alvim. Estabilidade e adaptabilidade como objetivos do direito: civil Law e common Law. Revista de Processo, São Paulo: RT, v. 172, ano 34, jun. 2009.

VICENTINO, Cláudio. História Geral. São Paulo: Scipione, 2000.

Informação bibliográfica deste texto, conforme a NBR 6023:2002 da Associação Brasileira de Normas Técnicas (ABNT):

SILVA, Francisco José Gomes da; AMORIM, Rosendo Freitas de. O garantismo jurídico no direito sindical. Direitos Fundamentais \& Justiça, Belo Horizonte, ano 12, n. 38, p. 143-164, jan./jun. 2018.

Submetido: 13.12 .2016

Pareceres: 10.04.2017, 05.04.2017

Aprovado: 07.02.2018 